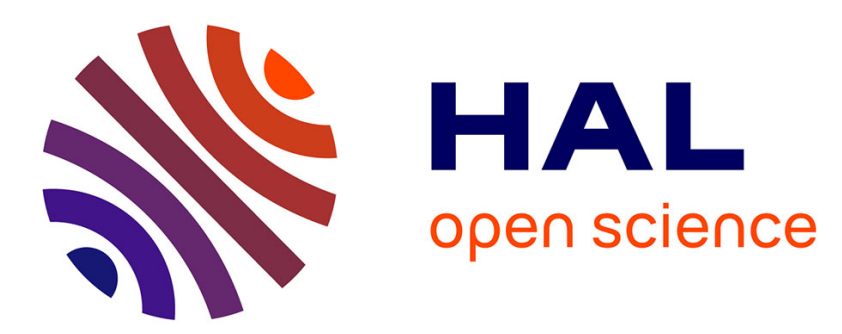

\title{
Inelastic Light Scattering Contribution to the Study of the Onset of Sintering of a Nanopowder
}

\author{
L. Saviot, S. Le Gallet, F. Demoisson, Laurent David, Guillaume Sudre, A.
} Girard, Jeremie Margueritat, A. Mermet

\section{- To cite this version:}

L. Saviot, S. Le Gallet, F. Demoisson, Laurent David, Guillaume Sudre, et al.. Inelastic Light Scattering Contribution to the Study of the Onset of Sintering of a Nanopowder. Journal of Physical Chemistry C, 2017, 121 (4), pp.2487-2494. 10.1021/acs.jpcc.6b12280 . hal-01637201

\section{HAL Id: hal-01637201 https://hal.science/hal-01637201}

Submitted on 4 Jun 2021

HAL is a multi-disciplinary open access archive for the deposit and dissemination of scientific research documents, whether they are published or not. The documents may come from teaching and research institutions in France or abroad, or from public or private research centers.
L'archive ouverte pluridisciplinaire HAL, est destinée au dépôt et à la diffusion de documents scientifiques de niveau recherche, publiés ou non, émanant des établissements d'enseignement et de recherche français ou étrangers, des laboratoires publics ou privés. 


\title{
Inelastic Light Scattering Contribution to the Study of the Onset of Sintering of a Nanopowder
}

\author{
L. Saviot, ${ }^{*}{ }^{\dagger}$ S. Le Gallet, ${ }^{\dagger}$ F. Demoisson, ${ }^{\dagger}$ L. David, ${ }^{\ddagger}$ G. Sudre, ${ }^{\ddagger}$ A. Girard, ${ }^{\S}$ J. Margueritat, ${ }^{\S}$ \\ and A. Mermet ${ }^{\$}$ \\ †Laboratoire Interdisciplinaire Carnot de Bourgogne UMR 6303 CNRS-Université de Bourgogne Franche-Comté, 9 av. A. Savary, BP \\ 47870, 21078 Dijon Cedex, France \\ "Ingénierie des Matériaux Polymères Université Lyon, Université Claude Bernard Lyon 1, CNRS UMR 5223, 15 bd A. Latarjet, \\ 69622, Villeurbanne, France \\ ${ }^{\S}$ Institut Lumière Matière, Université Lyon, Université Claude Bernard Lyon 1, CNRS UMR 5306, 69622 Villeurbanne, France
}

The onset of the sintering of $5 \mathrm{~nm} \mathrm{ZrO}_{2}$ and $\mathrm{TiO}_{2}$ nanoparticles is investigated by various methods including inelastic light scattering. A special attention is paid to low-frequency Raman spectra where scattering from confined acoustic vibrations and quasielastic scattering manifest. Significant changes are observed between samples sintered at different temperatures or applied forces. A detailed analysis of the spectra enables to follow the variation of the size of the nanoparticles, the surface area, and the formation of internanoparticles necks in the sintered materials. Finally, low-frequency scattering is shown to be more sensitive to the onset of sintering than most other experimental methods.

\section{INTRODUCTION}

Nanoparticles (NPs) attract a large attention because they can exhibit quite different properties compared to bulk materials. ${ }^{1} \mathrm{~A}$ major challenge in material science is to take advantage of their very small size and resulting properties at the macroscopic level. NPs sintering is a well-known strategy to reach this goal and ideally obtain ceramics with nanograins and enhanced tenacity. However, sintering may alter the NPs and/or the medium surrounding each of them which in turn alters their original functional properties. Thus, a good understanding of the sintering process at the NP level is required to finely tune the sintering conditions. For this reason, the sintering of various systems including metallic ${ }^{2-6}$ and oxide ${ }^{7-12}$ NPs has been studied in the past by a variety of experimental techniques. Only a few works have considered using vibrational spectroscopies and in particular Raman scattering to follow the sintering process. ${ }^{11-13}$ In addition, in those few cases, Raman scattering was restricted to monitoring the structure of the material (i.e.,crystalline or amorphous structure for example). However, significant changes in the low-frequency Raman spectra have been reported for annealed 3D supercrystals of NPs. ${ }^{14,15}$ To the best of our knowledge, no works have considered monitoring sintering through the observation of acoustic vibrations (lowfrequency range). The goal of the present work is to focus on low-frequency inelastic light scattering in order to assess the suitability of this experimental approach for the study of sintered nanomaterials.

In the following, we are concerned with the sintering of anatase $\mathrm{TiO}_{2}$ and monoclinic $\mathrm{ZrO}_{2} \mathrm{NPs}$ having initial diameters of about $5 \mathrm{~nm}$. We focus on the early stages of sintering so that the size of the NPs is not changed much. Several experimental methods are considered to monitor the changes at the nanometer scale resulting from sintering. A special attention is paid to low-frequency vibrations which are acoustic vibrations confined in the NPs. Their observation by Raman scattering is one of the original features of nanoobjects. Low-frequency Raman spectra of such nanoparticles have already been carefully investigated and confronted with X-ray diffraction (XRD) and high-resolution transmission electron microscopy measurements in previous works. ${ }^{16,17}$ In this work, vibrational spectra are measured to check whether this property is preserved after sintering and also to monitor the changes resulting from sintering. To help assign the origin of the changes in the spectra, relevant structural parameters (microstructure, mass density, size of the NPs, surface area) have been determined using other experimental techniques, namely scanning electron microscopy (SEM), Archimedes' method, XRD, small-angle Xray scattering (SAXS) and Brunauer-Emmett-Teller analysis (BET).

Oxide NPs are used in this work mostly as convenient model nanosystems. However, it should be noted that sintering in the conditions given above makes it possible to obtain bulk materials which are strong enough to be considered for specific applications. For example, original phononic properties are 
expected exploiting the acoustic properties of the individual NPs. This is similar to ultrasonic properties of sintered millimeter-sized beads: ${ }^{18,19}$ bands and gaps in the ultrasonic transmission have been related to the vibrations of the individual beads. Using NPs enables one to reach the $\mathrm{THz}$ frequency range. Sintered NPs can therefore be considered to alter the propagation of $\mathrm{THz}$ acoustic waves. As a result, they have potential applications as nanoacoustic materials, i.e., nanostructured materials having the ability to guide, confine, delay or filter nanoacoustic vibrations (phonons).

\section{SYNTHESIS AND STRUCTURAL CHARACTERIZATIONS}

$\mathrm{TiO}_{2}$ and $\mathrm{ZrO}_{2}$ NPs were synthesized with a continuous hydrothermal production process under supercritical conditions from bis(ammonium lactato)titanium dihydroxide $(676 \mathrm{~K}, 30$ $\mathrm{MPa})$ and zirconyl nitrate salt $\mathrm{ZrO}\left(\mathrm{NO}_{3}\right)_{2}(773 \mathrm{~K}, 30 \mathrm{MPa})$ respectively, using a setup previously presented elsewhere. $^{16,17,20}$ Here, $0.17 \mathrm{~g}$ of $\mathrm{TiO}_{2}$ or $0.25 \mathrm{~g}$ of $\mathrm{ZrO}_{2}$ nanopowders was sintered in graphite molds (inner diameter $8 \mathrm{~mm}$ ) by spark plasma sintering (SPS) using an HP D 10 setup (FCT systeme $\mathrm{GmbH}$ ). The effects of the temperature and pressure were evaluated but not the effects of the heating rate, holding time and atmosphere. The heating rate was maintained at $50{ }^{\circ} \mathrm{C} \mathrm{min}^{-1}$. No holding time was applied. Sintering was carried out under vacuum $\left(5 \times 10^{2} \mathrm{mbar}\right)$. The applied force was $3 \mathrm{kN}$ unless stated otherwise.

The mass density of all the samples was determined using the Archimedes' method in distilled water. The relative mass density was calculated as the ratio of the mass density of the sintered samples to the theoretical value, namely 3.9 and 5.83 $\mathrm{g} / \mathrm{cm}^{3}$ for anatase $\mathrm{TiO}_{2}$ and monoclinic $\mathrm{ZrO}_{2}$ respectively. The resulting values are slightly overestimated for zirconia samples containing a small amount of tetragonal $\mathrm{ZrO}_{2}$. The variation of mass density as a function of the sintering temperature is presented in Figure 1. In the low sintering temperature range (i.e., below $500{ }^{\circ} \mathrm{C}$ for $\mathrm{ZrO}_{2}$ and below $300{ }^{\circ} \mathrm{C}$ for $\mathrm{TiO}_{2}$ ), density does not vary significantly whereas at higher temperatures, it increases as expected. For pellets with an initial relative mass density between 40 and $45 \%$, a $\simeq 7 \%$ increase is expected when the first sintering stage is achieved if densifying mechanisms are activated during this stage. ${ }^{21}$ At the end of the first sintering stage, the neck size is supposed to have reached 40 to $50 \%$ of the particle radius. It means that the neck formation occurs below 750 and $400{ }^{\circ} \mathrm{C}$ for $\mathrm{ZrO}_{2}$ and $\mathrm{TiO}_{2}$ respectively.

The morphology was studied by SEM with a JEOL JSM6400F setup. An image for the $\mathrm{ZrO}_{2}$ nanopowder is presented in Figure 2 (top left). The nanopowder consists in $\simeq 100 \mu \mathrm{m}$ large aggregates of NPs. An image for the interior of a sample sintered at $800{ }^{\circ} \mathrm{C}$ is also shown (top right, fracture surface). It was obtained from a broken sample. Images obtained for the $\mathrm{TiO}_{2}$ nanopowder and the sample sintered at $350{ }^{\circ} \mathrm{C}$ in Figure 2 (bottom) show aggregates of NPs having a platelet shape. The thickness of the sheets is about $100 \mathrm{~nm}$ while their lateral dimension is about $100 \mu \mathrm{m}$. In the sintered $\mathrm{TiO}_{2}$ and $\mathrm{ZrO}_{2}$ samples, the structure of the aggregates is still present. For $\mathrm{TiO}_{2}$, the sheets mostly stack up under the applied pressure as can be seen in the bottom right photo of Figure 2 showing the fracture surface. In this work, our main goal is to obtain lightly sintered samples resulting in the formation of internanoparticle necks. The presence and characteristics of aggregates in the size range from 100 to $1 \mu \mathrm{m}$ would need to be considered if dense
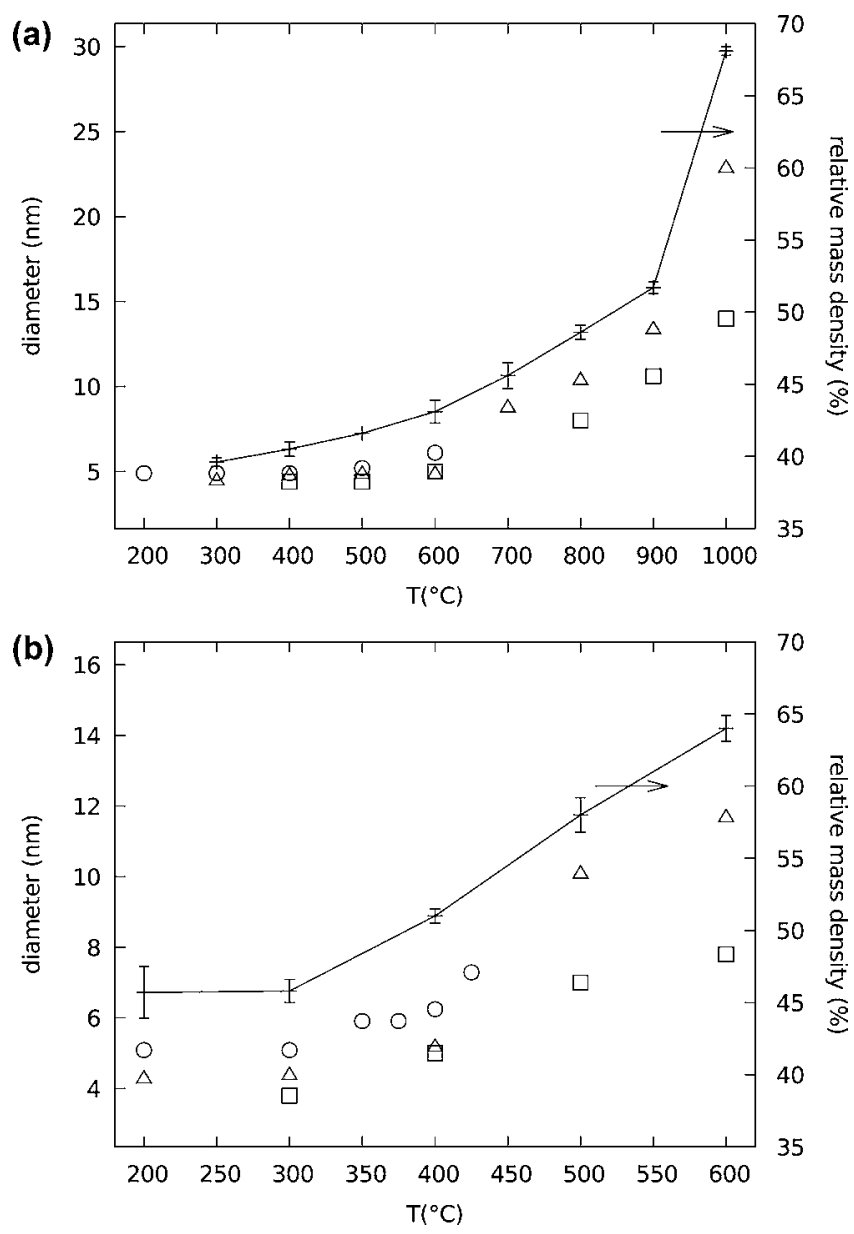

Figure 1. Variation of the relative mass density and diameter of the $\mathrm{ZrO}_{2}$ (a) and $\mathrm{TiO}_{2}$ (b) samples as a function of the sintering temperature. Mass densities are plotted with a line curve (right vertical axis). Diameters (left vertical axis) are determined from XRD (triangle), SAXS (square, $\pm 0.4 \mathrm{~nm}$ ) and low-frequency Raman (LFR) (circle).

sintered sample were to be obtained. In view of the difference in the size range, we will neglect this aggregate structure regarding the formation of inter-NPs necks in the following, because the first sintering steps occurs within the aggregates at the nanoparticle level.

The crystalline structure of the sintered samples was studied by XRD with a Bruker D8 Advance setup using the $\mathrm{Cu} \mathrm{K} \alpha$ radiation. For $\mathrm{TiO}_{2}$, only the reflections corresponding to the anatase lattice structure were observed. For $\mathrm{ZrO}_{2}$, the tetragonal lattice structure appears in the XRD patterns for sintering temperatures $T \geq 700{ }^{\circ} \mathrm{C}$ only. The diameters of the NPs were determined from the whole pattern fitting. The Pawley method ${ }^{22}$ was used for $\mathrm{TiO}_{2}$. For $\mathrm{ZrO}_{2}$, the Le Bail $\operatorname{method}^{23}$ was favored due to overlapping reflections. The variation of the crystallite diameters with the sintering temperature is presented in Figure 1 (squares, right vertical axis). Only the size for the monoclinic lattice structure is reported for $\mathrm{ZrO}_{2}$. Again, at low temperatures, the diameter does not vary significantly. The average diameter of the NPs starts to increase at the temperature corresponding to the end of the first sintering stage.

SAXS experiments were carried out at the European Synchrotron Radiation Facility (Grenoble, France) on the BM2 D2AM beamline. The incident energy was $16 \mathrm{keV}(\lambda=$ 


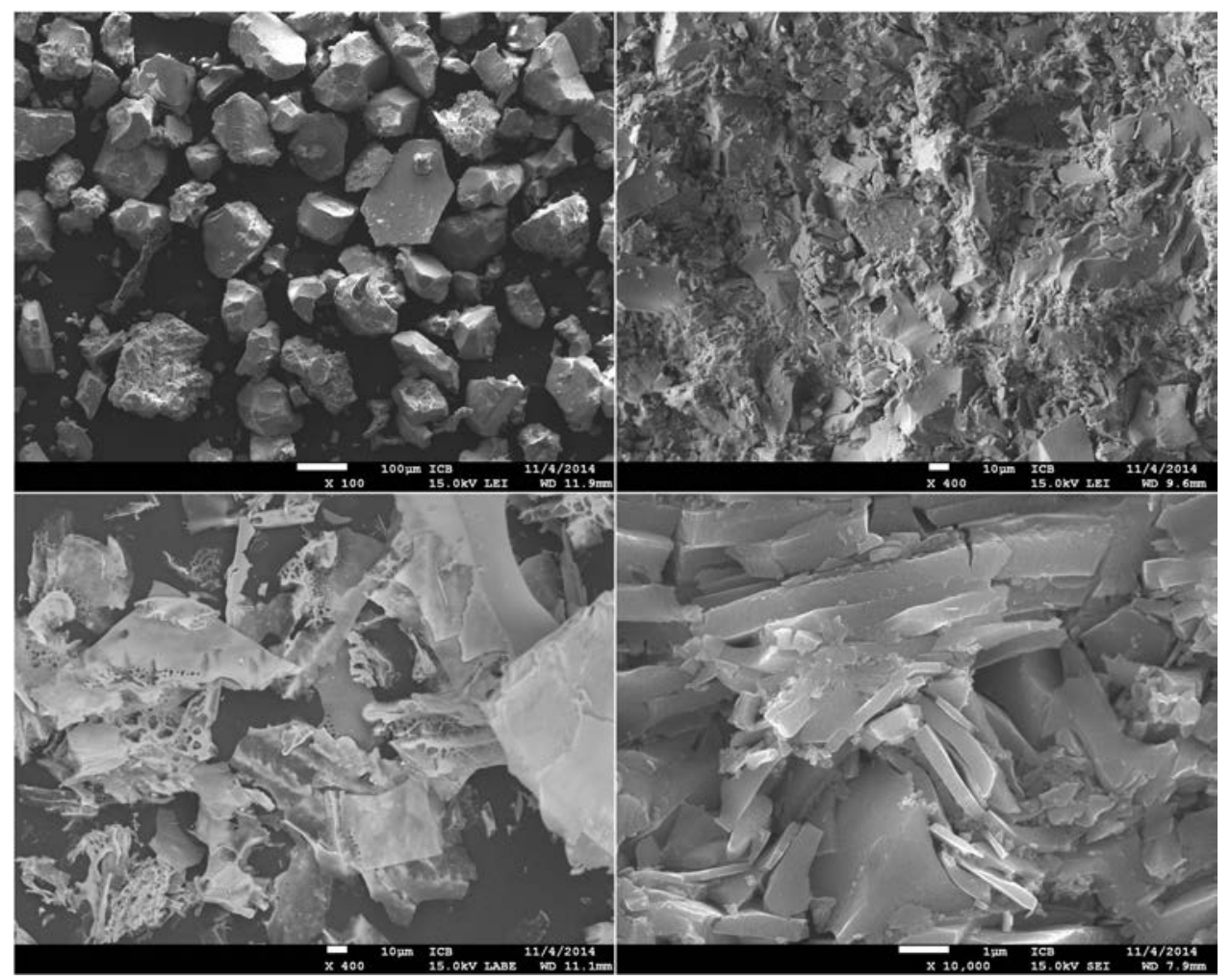

Figure 2. Top: SEM images of the $\mathrm{ZrO}_{2}$ nanopowder (left) and of the sample sintered at $800{ }^{\circ} \mathrm{C}$ (right). The scale bars measure 100 (left) and 10 $\mu \mathrm{m}$ (right). Bottom: $\mathrm{TiO}_{2}$ nanopowder (left) and sample sintered at $350{ }^{\circ} \mathrm{C}$ (right). The scale bars measure 10 (left) and $1 \mu \mathrm{m}$ (right).

$0.7748 \AA$ ). We used a CCD camera (Ropper Scientific), and the scattering diagrams $I(q)$ vs $q$ (where $q=4 \pi \sin (\theta) / \lambda$ is the scattering vector) were obtained after dark image subtraction, flat field correction, distortion correction, empty cell subtraction and finally azimuthal average over the image center. Gyration diameters $\left(2 R_{g}\right)$ were obtained by fitting the SAXS patterns with eq 1 . Their evolution with sintering temperature are plotted in Figure 1. The first term in eq 1 is due to the scattering from large objects (agglomerates). The second and third terms well reproduce the Guinier and Porod's law by the NPs net surface. See ref 24 for details.

$$
I(q)=\frac{C_{1}}{q^{\alpha}}+G \exp \left(-\frac{q^{2} R_{g}{ }^{2}}{3}\right)+B \frac{\left(\operatorname{erf}\left(\frac{q R_{g}}{\sqrt{6}}\right)\right)^{12}}{q^{4}}
$$

All data could not be analyzed through the unified Beaucage law in eq 1. In particular, at higher sintering temperatures, interparticular ordering occurs (inside the aggregates) and results in a correlation halo. Thus, a structure factor $S(q)$ was introduced according to eq 2 :

$$
S(q)=\frac{1}{1+3 k \frac{\sin (q d)-q d \cos (q d)}{(q d)^{3}}}
$$

where $k$ is an order parameter and $d$ is the interparticle correlation distance. ${ }^{24}$ For both materials, we observed that $k$ increases with the sintering temperature. For $\mathrm{ZrO}_{2}, k=0$ (i.e., $S(q)=1)$ for $T \leq 600{ }^{\circ} \mathrm{C}$ which means that there is no ordering in the original nanopowder. The same is true for $\mathrm{TiO}_{2}$ for $T \leq 400{ }^{\circ} \mathrm{C}$. This rules out the existence of an ordered arrangement of the NPs inside the initial nanopowders.
Nitrogen adsorption isotherms were measured at $77 \mathrm{~K}$ on an ASAP2020 Micromeritics setup. Before measurements the samples were outgassed at $150{ }^{\circ} \mathrm{C}$ for $10 \mathrm{~h}$. The surface areas were calculated following the BET theory in the 0.05-0.2 relative pressure range. The values of surface area were measured with a relative standard error of $10 \%$. The adsorption average pore width obtained from the adsorption branch of the isotherms by the Barrett-Joyner-Halenda $(\mathrm{BJH})$ analysis are 3.6 and $5.5 \mathrm{~nm}$ for $\mathrm{ZrO}_{2}$ at 300 and $700{ }^{\circ} \mathrm{C}$ and 2.9 and $4.5 \mathrm{~nm}$ for $\mathrm{TiO}_{2}$ at 200 and $600{ }^{\circ} \mathrm{C}$ respectively. These are assigned to the pores in-between the NPs. The average pore width increases due to the increase of average diameter of the NPs and also because the smallest pores disappear first. The isotherm linear plots evidenced also micropores. The macropores observed by SEM (between large aggregates) were not characterized by this analysis. Additionally, we can further focus on the differences between the $\mathrm{TiO}_{2}$ and $\mathrm{ZrO}_{2}$ samples. Organic precursors were used to synthesize the $\mathrm{TiO}_{2} \mathrm{NPs}$ only. Thus, some organic moieties remain at the surface of the NPs even after multiple washings. They manifest in the Raman spectra through $\mathrm{C}-\mathrm{H}$ stretching peaks for sintering temperatures $T<400{ }^{\circ} \mathrm{C}\left(2800-3000 \mathrm{~cm}^{-1}\right.$ range, not shown $)$. As the temperature during sintering increases, these peaks disappear, photoluminescence due to the carbon moieties is observed, and the usual D and G bands of amorphous carbon appear for $T \geq$ $600{ }^{\circ} \mathrm{C}$ (not shown). The color of the samples is also affected. The $\mathrm{TiO}_{2}$ samples becomes darker and darker as the sintering temperature increases. However, the amount of organic content is very small. A significant amount of organic species inbetween the NPs would have hindered the growth of the NPs which is not what we observed. For this reason, we neglect their role in most measurements except for the additional Raman 
peaks. They may also play a minor role in the surface area measurements (BET).

\section{INELASTIC LIGHT SCATTERING}

We now investigate the same samples using low-frequency Raman (LFR) scattering. Raman spectra were measured using a Renishaw inVia setup equipped with a low-frequency notch filter made of BraggGrate volume Bragg gratings with a $532 \mathrm{~nm}$ laser excitation. In the following the spectra are normalized so that the intensity of the most intense optical phonons peak is unity. The Raman spectra for the $\mathrm{ZrO}_{2}$ and $\mathrm{TiO}_{2}$ samples sintered at different temperatures are presented in Figure 3 and 4 respectively.

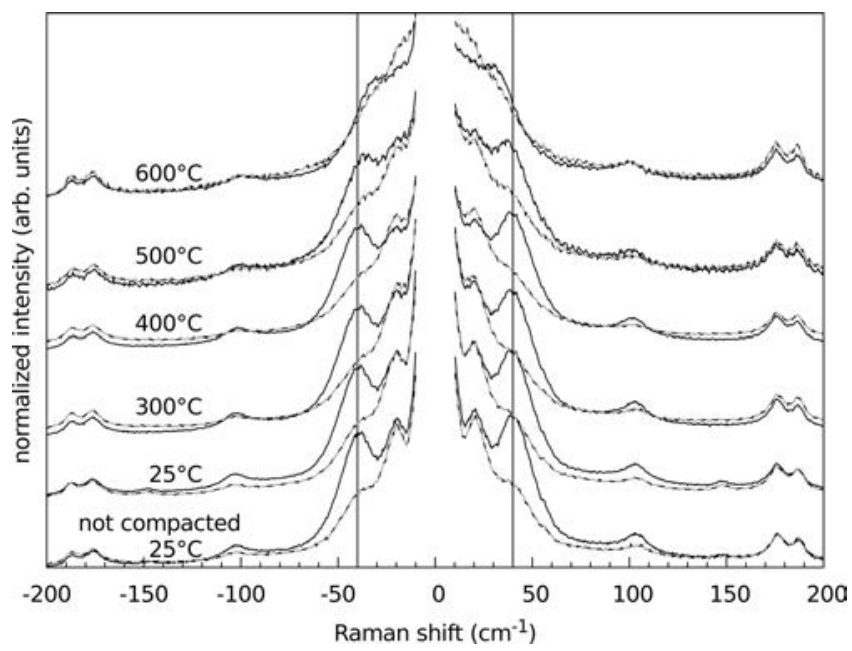

Figure 3. Room temperature low-frequency Raman spectra of the $\mathrm{ZrO}_{2}$ samples sintered at different temperatures. The spectra are vertically shifted for clarity. The bottom spectrum corresponds to the uncompacted NPs. The continuous and broken lines correspond to the spectra measured with the incident and scattered polarizations being parallel and crossed, respectively. The vertical lines are guide for the eye to emphasize the shift of the $l=0$ peak.

Size Variation. Spectra measured for the raw nanopowders have already been described in details previously. ${ }^{16,17}$ In order to describe their acoustic vibrations, the NPs are modeled as spheres in the framework of continuum elasticity. ${ }^{25}$ The quadrupolar (angular momentum $l=2$, lowest frequency) and breathing $(l=0)$ spheroidal modes are observed for both samples but the relative intensity of the breathing mode is quite small for $\mathrm{TiO}_{2}{ }^{26-28}$ Peaks centered at Raman shifts larger than $80 \mathrm{~cm}^{-1}$ are due to optical phonons of anatase titania or monoclinic zirconia. For $\mathrm{ZrO}_{2}$, the $150 \mathrm{~cm}^{-1}$ peak is due to a small amount of the metastable tetragonal lattice structure. It disappears after moderate heating and reappears only for sintering temperatures above $700{ }^{\circ} \mathrm{C}$ (data not shown). Only the scattering by the breathing mode is polarized which means that its intensity vanishes when the polarization of the scattered light is perpendicular to the polarization of the incident light (see Figure 3). The frequency of both vibrations varies as the inverse diameter of the NPs $(\nu=K / d$ where the proportionality coefficient $K$ can be calculated ${ }^{25}$ for each mode symmetry using the sound speeds in the material the NPs are made of). This allowed us to determine the average size of the NPs from the position of the maximum of the LFR peaks. For $\mathrm{ZrO}_{2}$ we used the $l=0$ Raman peak for better accuracy. ${ }^{17}$ The resulting diameters are plotted in Figure 1. For both investigated

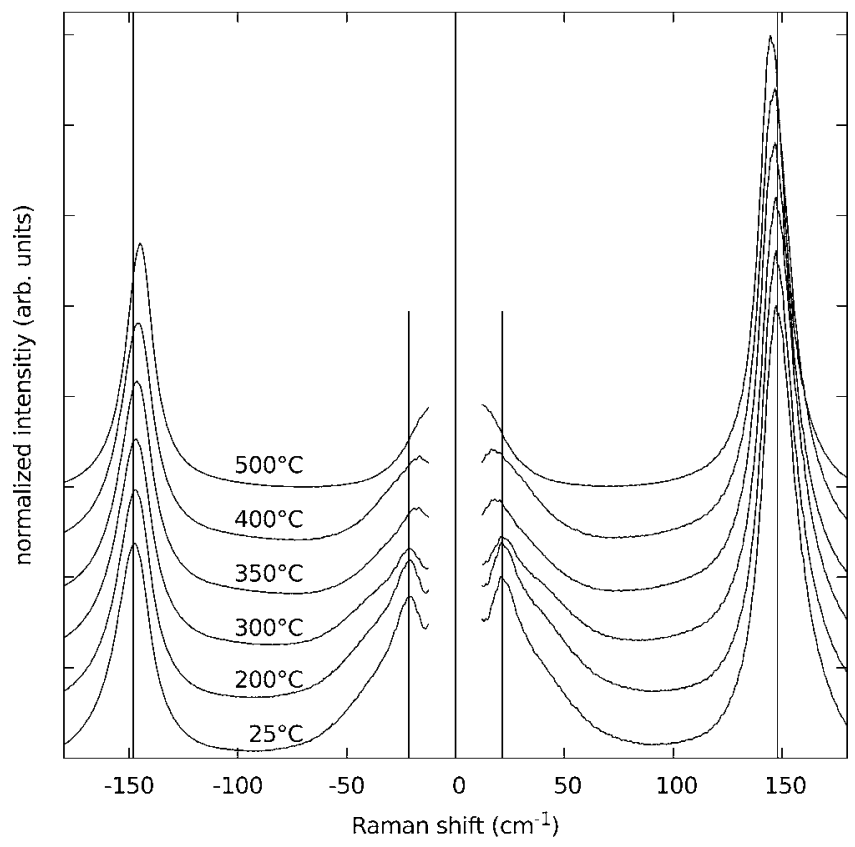

Figure 4. Room temperature low-frequency Raman spectra of the $\mathrm{TiO}_{2}$ samples sintered at different temperatures. The spectra are vertically shifted for clarity.

systems, the diameters are a bit larger but quite similar to those determined from XRD and SAXS measurements. In spite of these differences, the sintering temperature at which the NPs start to grow is the same whatever the experimental method used to obtain the average diameters. Optical phonon peaks can also be used to derive the diameter of the NPs. ${ }^{16}$ This method will not be detailed as optical phonons peaks are also quite sensitive to a variety of other factors namely oxygen stoichiometry, temperature, strain and disorder. However, we note in the case of $\mathrm{TiO}_{2}$ that the shape of the intense $\mathrm{E}_{\mathrm{g}}$ peak at about $150 \mathrm{~cm}^{-1}$ changes for sintering temperatures above $300{ }^{\circ} \mathrm{C}$ too.

Relative Intensities. Another significant change in the LFR spectra concerns the relative intensities of the low-frequency scattering peaks. Focusing first on $\mathrm{TiO}_{2}$ samples in Figure 4, we note that the low-frequency peak position is unchanged between 200 and $300{ }^{\circ} \mathrm{C}$ (i.e., same average diameter) but its relative intensity is reduced. Figure 5 shows the intensity ratio of the low-frequency to optical phonon peaks for all the samples. It was calculated according to the following procedure. First a linear background is removed from all the spectra so that the remaining intensity is due only to Raman and quasielastic scattering. For $\mathrm{TiO}_{2}$ the low-frequency intensity is summed between 12 and $100 \mathrm{~cm}^{-1}$. The optical band is integrated between 100 and $200 \mathrm{~cm}^{-1}$. For $\mathrm{ZrO}_{2}$ the low-frequency intensity is summed between 12 and $80 \mathrm{~cm}^{-1}$ and the optical band between 160 and $200 \mathrm{~cm}^{-1}$. The resulting ratios are then divided by the value obtained for nonheated samples $\left(25^{\circ} \mathrm{C}\right)$.

The obtained ratios differ significantly between the nonheated compacted samples and the samples sintered at 300 and $400{ }^{\circ} \mathrm{C}$ for $\mathrm{TiO}_{2}$ and $\mathrm{ZrO}_{2}$ respectively. These temperatures are lower than those at which the diameters start to increase. In the following, we discuss the reasons for this variation.

Quasielastic Scattering. At least part of the LFR intensity is due to quasielastic scattering. It concerns scattering by anharmonic motions such as localized and weakly thermally activated relaxations of molecular groups as observed in liquid 


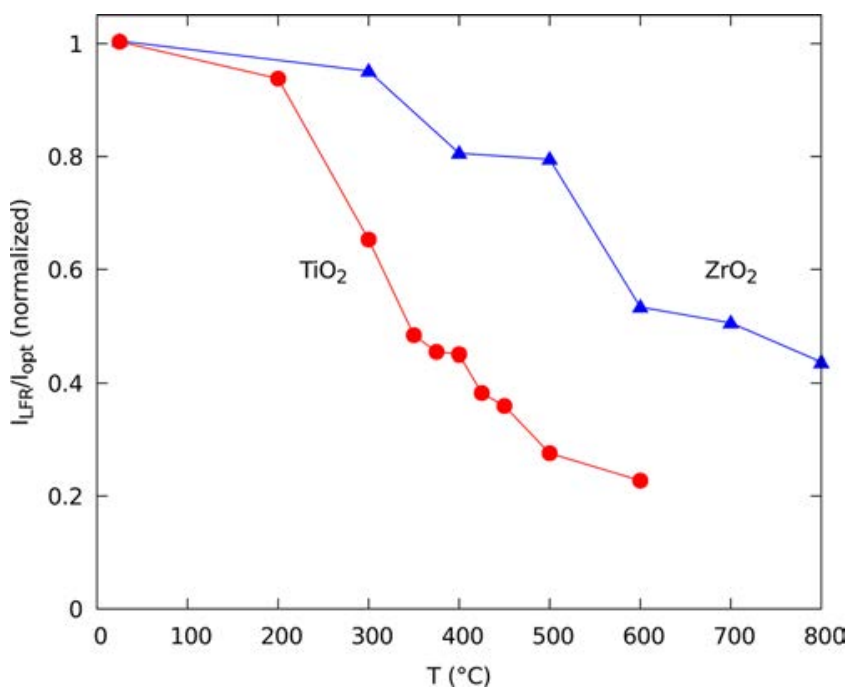

Figure 5. Normalized ratio of the low-frequency and optical Stokes bands intensities as a function of the sintering temperature.

and glasses for example. It manifests in the spectra as a broad peak centered at the origin and in the same frequency range as the low-frequency Raman peaks. Its intensity decreases significantly with temperature. Spectra measured at 100 and $300 \mathrm{~K}$ for two $\mathrm{TiO}_{2}$ samples are presented in Figure 6. As

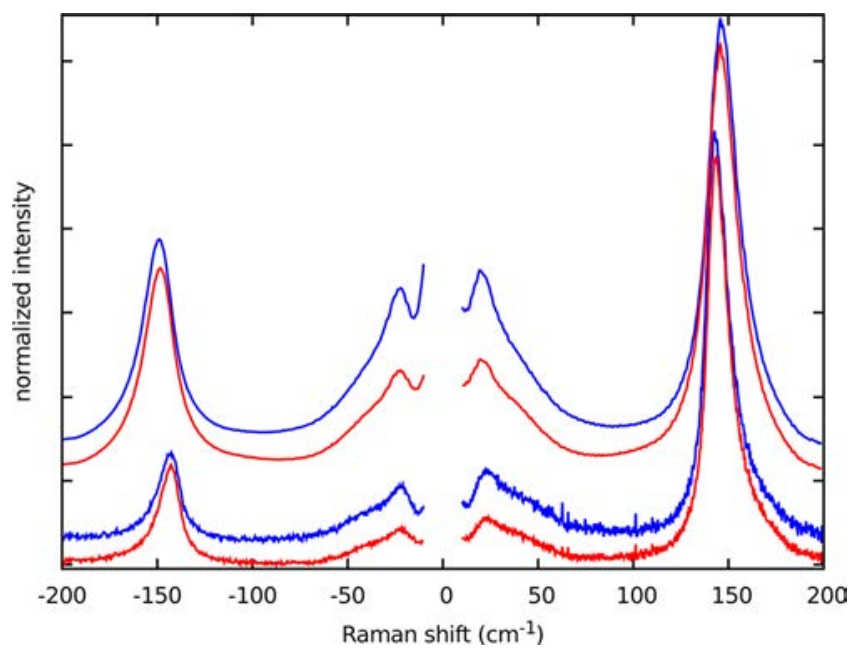

Figure 6. Normalized LFR spectra at room temperature (2 top spectra) and $T \simeq 100 \mathrm{~K}$ ( 2 bottom spectra) of $\mathrm{TiO}_{2} \mathrm{NPs}$ compacted (blue) and sintered at $300{ }^{\circ} \mathrm{C}$ (red). The spectra are vertically shifted for clarity.

expected, the phonon bands are slightly shifted when cooling the samples. But we also observe a large decrease of the lowfrequency intensity with respect to that of the optical phonons. This confirms the existence of a significant quasielastic scattering contribution for both samples measured at room temperature.

Since quasielastic scattering mostly originates from surface atoms and species, this decrease can be assigned to either a decrease in the dynamics due to a reorganization (annealing) of the NPs surface or to a decrease of the surface area due to the formation of necks. In order to distinguish between these two possible origins, we compared the Raman spectra measured for the same sintering temperature but at different applied forces.
Figure 7 was obtained for $\mathrm{ZrO}_{2}$ samples sintered at $400{ }^{\circ} \mathrm{C}$ with applied forces of 3 and $5 \mathrm{kN}$. From a previous work by some of

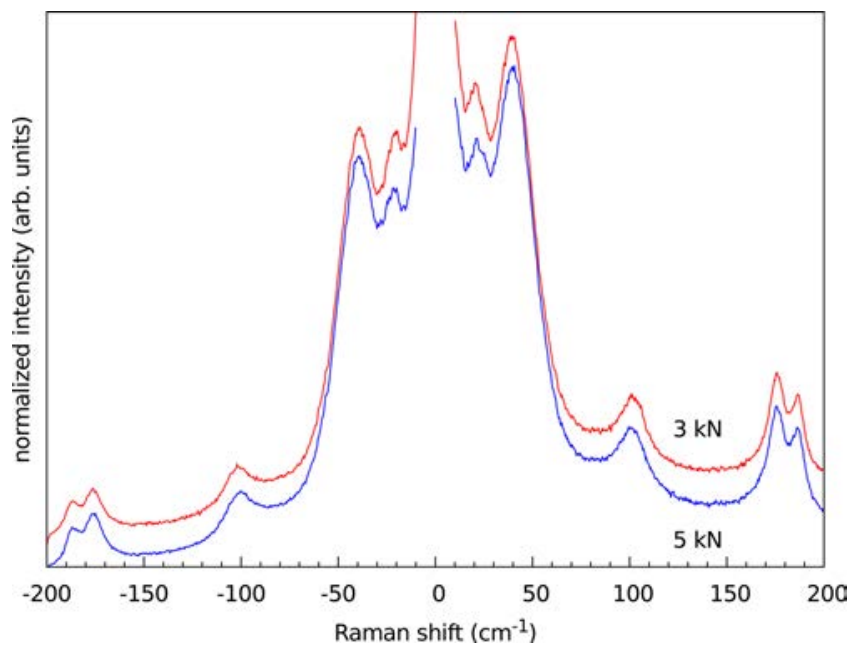

Figure 7. LFR spectra of $\mathrm{ZrO}_{2} \mathrm{NPs}$ sintered at $400{ }^{\circ} \mathrm{C}$ with an applied force of 3 (top) and $5 \mathrm{kN}$ (bottom). The spectra are vertically shifted for clarity.

us, $^{29}$ we know that GPa pressures are required to impact the confined acoustic vibrations. Therefore, we expect no changes due to the applied forces used in this work because 3 and $5 \mathrm{kN}$ correspond to 60 and $100 \mathrm{MPa}$, respectively. However, we note that the low-frequency intensities differ between the two samples sintered at $400{ }^{\circ} \mathrm{C}$ close to the Rayleigh line. An applied force is known to promote the formation of necks in the early stages of sintering. We thus conclude that the formation of necks is responsible for the decrease of the quasielastic scattering intensity.

We now compare the variation of the Raman intensity ratio with temperature to the variation of the surface area as measured by BET. For $\mathrm{ZrO}_{2}$ between 300 and $700{ }^{\circ} \mathrm{C}$, the BET surface and the Raman intensity ratio are multiplied by 0.50 and 0.53 respectively. For $\mathrm{TiO}_{2}$ between 200 and $600{ }^{\circ} \mathrm{C}$, the BET surface and the Raman intensity ratio change by a factor by 0.27 and 0.24 respectively. This quantitative agreement supports our assignment of most of the low-frequency intensity to quasielastic scattering by surface species.

Low-Frequency Vibrations. In this section, we address if the intensity ratio decrease is related to the intensity of the LFR peaks too. To answer this question, it is necessary to remove all non-Raman contributions from the spectra including quasielastic scattering. This could be achieved by fitting the spectra but this would require introducing many unknown parameters in order to reproduce all the spectral features. Instead, we resorted to a different approach. The Stokes Raman intensity is $I(\omega)=I_{r}(\omega)(n(\omega)+1)$ and the anti-Stokes intensity is $I(-\omega)$ $=I_{r}(\omega) n(\omega)$ with $n(\omega)=\left[\exp \left(\frac{\hbar \omega}{k_{\mathrm{B}} T}\right)-1\right]^{-1}$ and $\omega>0$. We note that $I_{r}$, the Raman intensity without the thermal population factor, can be expressed as $I_{r}(\omega)=I(\omega)-I(-\omega)$. By calculating $I_{r}$ using this method, the symmetrical nonRaman contributions to the spectra are also removed. This is the case for quasielastic scattering. A constant background due to the dark signal of the detector or photoluminescence are also removed. We applied this method for $\mathrm{TiO}_{2}$ in order to suppress the quasielastic scattering contribution. The resulting spectra 


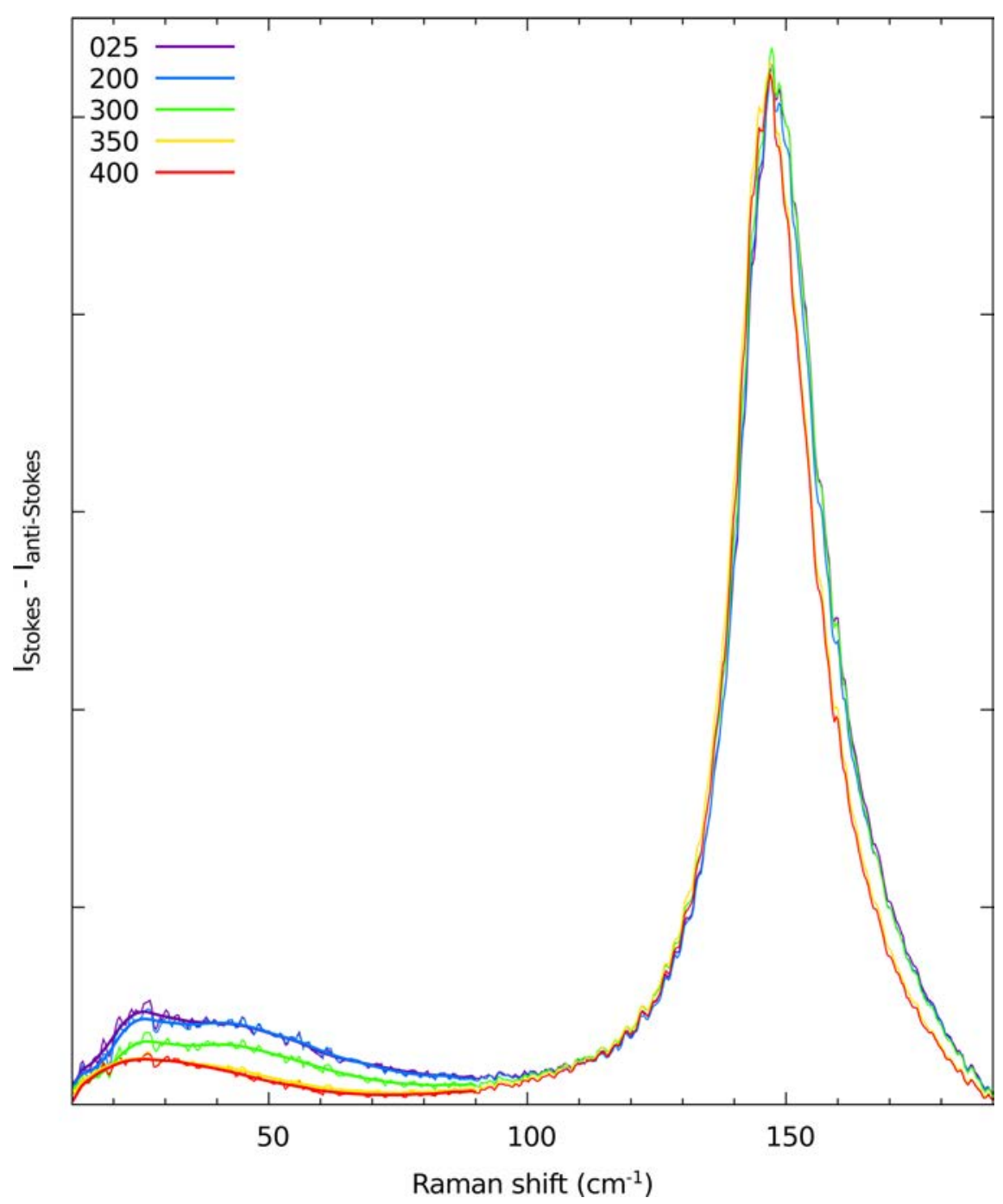

Figure 8. Stokes and anti-Stokes difference Raman spectra of $\mathrm{TiO}_{2}$ samples sintered at different temperatures. Smoothed curves are also plotted below $90 \mathrm{~cm}^{-1}$ with thicker lines as guide for the eye due to the increased signal-to-noise ratio resulting from the calculation of the difference spectra.

are plotted in Figure 8. The intensity at very low frequency is significantly diminished when the thermal population factors is not present because $n(\omega) \rightarrow \infty$ when $\omega \rightarrow 0$. This results in a significant decrease of the intensity ratio of the quadrupolar mode to the breathing mode. The $l=0$ peak which appeared only as a weak shoulder in the original spectra is now clearly observed. It is centered at about $45 \mathrm{~cm}^{-1}$ for samples sintered at $300{ }^{\circ} \mathrm{C}$ or less. In the optical phonon range, the spectra for the samples sintered at $T \leq 300{ }^{\circ} \mathrm{C}$ are identical within experimental accuracy. The $\mathrm{E}_{\mathrm{g}}$ peak becomes narrower and shifts toward lower frequencies and the $l=0$ peak shifts toward lower frequencies for $T \geq 350{ }^{\circ} \mathrm{C}$. This is related to the increase of the average diameter of the NPs. However, a significant decrease of the low-frequency Raman intensity at $300{ }^{\circ} \mathrm{C}$ can be observed, i.e., at sintering temperatures below the temperature range where the average diameter increases. We also applied the same procedure to $\mathrm{ZrO}_{2}$ samples. However, due to the smaller Raman scattering cross-section, the calculation of $I_{r}(\omega)$ resulted in spectra with a significant noise. Still the same behavior could qualitatively be observed, namely a decrease of the normalized low-frequency Raman intensity at $400{ }^{\circ} \mathrm{C}$, i.e., before the increase of the average diameter.
We assign this decrease of the LFR peaks intensities to a modification of the low-frequency vibrations due to the appearance of necks in-between NPs. Previous works ${ }^{30}$ have shown the hybridization of confined acoustic vibrations of weakly coupled NPs. A similar process is at work during the early stages of sintering.

Long Wavelength Acoustic Vibrations. We also checked the suitability of Brillouin scattering (BS) to investigate the onset of NPs sintering. This light scattering method was shown to be very sensitive to the arrangement of NPs in a nanopowder and in particular to the inter-NP interactions. ${ }^{31,32} \mathrm{BS}$ is also due to inelastic scattering by acoustic vibrations. However, the involved propagating acoustic waves have wavelengths closer to those of the incident photons, i.e., a few hundreds of $\mathrm{nm}$ therefore much larger than the actual size of NPs contrarily to what was discussed above in the low-frequency range.

The position of the Brillouin peak measured for the different samples are presented in Figure 9. The Brillouin setup is a sixpass tandem Fabry-Perot interferometer with a $532 \mathrm{~nm}$ laser excitation. In the temperature range of interest the BS frequency changes are small. A standard deviation of \pm 1.2 $\mathrm{GHz}$ is obtained by statistical analysis of various measurements at different places on the same sample, as shown for $\mathrm{ZrO}_{2}$ 


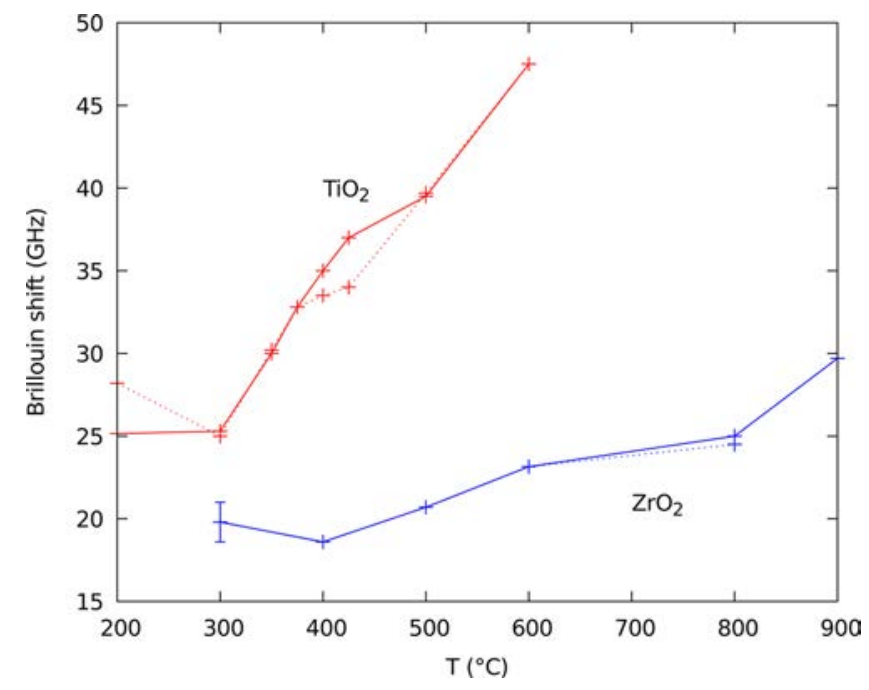

Figure 9. Brillouin peak position for $\mathrm{TiO}_{2}$ (red) and $\mathrm{ZrO}_{2}$ (blue) samples obtained from parallel (continuous line) and crossed (dotted) polarizations spectra as a function of the sintering temperature. A typical error bar is shown for the lowest temperature $\mathrm{ZrO}_{2}$ measurement.

sintered at $300{ }^{\circ} \mathrm{C}$. It makes it difficult to determine accurately the temperature threshold at which sintering may impact the Brillouin shift. Still, the onset for changes in $\mathrm{TiO}_{2}$ samples seems to be for sintering temperatures $T>300{ }^{\circ} \mathrm{C}$, i.e., above the one determined from the LFR spectra. No such onset can be determined reliably for $\mathrm{ZrO}_{2}$ due to the small observed variation. The Brillouin shift variation is related to the variations of the mass density and refraction index of the material and the formation of necks between neighbor NPs. ${ }^{31,32}$ All these different contributions result in a complex dependence of the Brillouin shift on the sintering temperature whose careful investigation goes beyond the scope of this paper.

The variation of the Brillouin shift observed for $\mathrm{ZrO}_{2}$ is significantly smaller than the one for $\mathrm{TiO}_{2}$ despite the other observed variations (mass density, diameter of the NPs) being quite similar in the same temperature ranges. We tentatively relate this different behavior to the small amount of organic moieties at the surface of the $\mathrm{TiO}_{2}$ NPs. After sintering, it transforms into amorphous carbon. This may increase the stiffness of a few interparticle bonds and result in larger sound speeds and therefore larger Brillouin frequencies.

\section{CONCLUSION}

We have successfully synthesized monodisperse $\mathrm{ZrO}_{2}$ and $\mathrm{TiO}_{2}$ nanopowders in sufficient amounts to study the onset of their sintering. A detailed inelastic light scattering analysis established their suitability to follow the initial changes occurring in the nanopowders. The Raman peaks originating from confined acoustic and optical phonons were shown to depend on the size of the NPs in agreement with XRD and SAXS measurements. The decrease of the relative intensity of the acoustic phonon peaks was also reported without any substantial change in the peak shapes. This has been tentatively assigned to the appearance of coupled inter-NP vibrations due to the formation of necks between sintered NPs. However, narrower size distributions (or few NPs measurements) are required in order to push forward the study of such coupled vibrations. In addition, the quasielastic peak assigned to relaxation motions of surface species was shown to be very sensitive to changes occurring before the growth of the NPs. The variation of the quasielastic intensity with sintering temperature matches quantitatively the variation of the surface area as measured by the BET method. Finally, for both compositions, larger temperatures or applied forces were required during sintering for changes to be observed in the optical phonon range rather than in the low-frequency range. These results demonstrate that low-frequency Raman scattering is a promising method to follow the sintering process. For nanopowders for which the observation of well-defined low-frequency acoustic peaks is not possible due to the NPs being too large or the size distribution being too broad, the sintering process can still be monitored using the quasielastic scattering intensity.

\section{AUTHOR INFORMATION Corresponding Author \\ *(L.S.) E-mail: lucien.saviot@u-bourgogne.fr. ORCID $\odot$}

L. Saviot: 0000-0002-1249-2730

\section{Notes}

The authors declare no competing financial interest.

\section{ACKNOWLEDGMENTS}

The authors thank Ludivine Minier, Igor Bezverkhyy, Nicolas Geoffroy, and Frédéric Herbst for their assistance with SPS and the BET, XRD, and SEM measurements.

\section{REFERENCES}

(1) Pan, N.; Wang, B.; Wang, X.; Hou, J. G. Manipulating and Tailoring the Properties of 0-D and 1-D Nanomaterials. J. Mater. Chem. 2010, 20, 5567-5581.

(2) Asoro, M.; Ferreira, P.; Kovar, D. In Situ Transmission Electron Microscopy and Scanning Transmission Electron Microscopy Studies of Sintering of Ag and Pt Nanoparticles. Acta Mater. 2014, 81, 173183.

(3) Larsson, E. M.; Millet, J.; Gustafsson, S.; Skoglundh, M.; Zhdanov, V. P.; Langhammer, C. Real Time Indirect Nanoplasmonic In Situ Spectroscopy of Catalyst Nanoparticle Sintering. ACS Catal. 2012, 2, 238-245.

(4) Arcidiacono, S.; Bieri, N.; Poulikakos, D.; Grigoropoulos, C. On the Coalescence of Gold Nanoparticles. Int. J. Multiphase Flow 2004, 30, 979-994.

(5) Martin, T. E.; Gai, P. L.; Boyes, E. D. Dynamic Imaging of Ostwald Ripening by Environmental Scanning Transmission Electron Microscopy. Chem CatChem 2015, 7, 3705-3711.

(6) Zhang, Y.; Wu, L.; El-Mounayri, H.; Brand, K.; Zhang, J. Molecular Dynamics Study of the Strength of Laser Sintered Iron Nanoparticles. Procedia Manufacturing 2015, 1, 296-307.

(7) Widiyastuti, W.; Lee, S. Y.; Iskandar, F.; Okuyama, K. Sintering Behavior of Spherical Aggregated Nanoparticles Prepared by Spraying Colloidal Precursor in a Heated Flow. Adv. Powder Technol. 2009, 20, 318-326.

(8) Teleki, A.; Wengeler, R.; Wengeler, L.; Nirschl, H.; Pratsinis, S. Distinguishing Between Aggregates and Agglomerates of Flame-Made $\mathrm{TiO}_{2}$ by High-Pressure Dispersion. Powder Technol. 2008, 181, 292300.

(9) Buesser, B.; Gröhn, A. J.; Pratsinis, S. E. Sintering Rate and Mechanism of $\mathrm{TiO}_{2}$ Nanoparticles by Molecular Dynamics. J. Phys. Chem. C 2011, 115, 11030-11035.

(10) Srdić, V. V.; Winterer, M.; Hahn, H. Sintering Behavior of Nanocrystalline Zirconia Prepared by Chemical Vapor Synthesis. J. Am. Ceram. Soc. 2000, 83, 729-736.

(11) Ivanda, M.; Clasen, R; Hornfeck, M.; Kiefer, W. Raman Spectroscopy on $\mathrm{SiO}_{2}$ Glasses Sintered from Nanosized Particles. J. Non-Cryst. Solids 2003, 322, 46-52. 
(12) Buscarino, G.; Ardizzone, V.; Vaccaro, G.; Agnello, S.; Gelardi, F. M. Atomic Force Microscopy and Raman Investigation on the Sintering Process of Amorphous $\mathrm{SiO}_{2}$ Nanoparticles. J. Appl. Phys. 2010, 108, 074314.

(13) Yushin, G.; Osswald, S.; Padalko, V.; Bogatyreva, G.; Gogotsi, Y. Effect of Sintering on Structure of Nanodiamond. Diamond Relat. Mater. 2005, 14, 1721-1729.

(14) Mattarelli, M.; Montagna, M.; Still, T.; Schneider, D.; Fytas, G. Vibration Spectroscopy of Weakly Interacting Mesoscopic Colloids. Soft Matter 2012, 8, 4235-4243.

(15) Saviot, L.; Murray, D. B.; Caputo, G.; Marco de Lucas, M. C.; Pinna, N. THz Nanocrystal Acoustic Vibrations from $\mathrm{ZrO}_{2}$ 3D Supercrystals. J. Mater. Chem. C 2013, 1, 8108-8116.

(16) Pighini, C.; Aymes, D.; Millot, N.; Saviot, L. Low-Frequency Raman Characterization of Size-Controlled Anatase $\mathrm{TiO}_{2}$ Nanopowders Grown by Continuous Hydrothermal Synthesis. J. Nanopart. Res. 2007, 9, 309-315.

(17) Demoisson, F.; Ariane, M.; Saviot, L. Acoustic Vibrations of Monoclinic Zirconia Nanocrystals. J. Phys. Chem. C 2011, 115, 1457114575 .

(18) Turner, J. A.; Chambers, M. E.; Weaver, R. L. Ultrasonic Band Gaps in Aggregates of Sintered Aluminum Beads. Acta Acust. Acust. 1998, 84, 628-631.

(19) Hu, H.; Strybulevych, A.; Page, J. H.; Skipetrov, S. E.; van Tiggelen, B. A. Localization of Ultrasound in a Three-Dimensional Elastic Network. Nat. Phys. 2008, 4, 945-948.

(20) Demoisson, F.; Ariane, M.; Piolet, R.; Bernard, F. Original Supercritical Water Device For Continuous Production of Nanopowders. Adv. Eng. Mater. 2011, 13, 487-493.

(21) Haussonne, J.-M.; Barton, J. L.; Bowen, P.; Carry, C. P. Céramiques et Verres: Principes et Techniques d'Élaboration, 1st ed.; Traité des matériaux; Presses Polytechniques et Universitaires Romandes: Lausanne, Switzerland, 2005; Vol. 16; pp 1-830.

(22) Pawley, G. S. Unit-Cell Refinement from Powder Diffraction Scans. J. Appl. Crystallogr. 1981, 14, 357-361.

(23) Le Bail, A.; Duroy, H.; Fourquet, J. Ab-Initio Structure Determination of $\mathrm{LiSbWO}_{6}$ by X-Ray Powder Diffraction. Mater. Res. Bull. 1988, 23, 447-452.

(24) Beaucage, G.; Schaefer, D. W. Structural Studies of Complex Systems Using Small-Angle Scattering: a Unified Guinier/Power-Law Approach. J. Non-Cryst. Solids 1994, 172-174, 797-805.

(25) Lamb, H. On the Vibrations of an Elastic Sphere. Proc. London Math. Soc. 1881, s1-13, 189-212.

(26) Jouanne, M.; Morhange, J. F.; Kanehisa, M. A.; HaroPoniatowski, E.; Fuentes, G. A.; Torres, E.; Hernández-Tellez, E. Structural Transformations in Nanosized Zirconium Oxide. Phys. Rev. B: Condens. Matter Mater. Phys. 2001, 64, 155404.

(27) Ivanda, M.; Furić, K.; Musić, S.; Ristić, M.; Gotić, M.; Ristić, D.; Tonejc, A. M.; Djerdj, I.; Mattarelli, M.; Montagna, M.; et al. Low Wavenumber Raman Scattering of Nanoparticles and Nanocomposite Materials. J. Raman Spectrosc. 2007, 38, 647.

(28) Ivanda, M.; Car, D.; Mikac, L.; Ristić, D.; Đerek, V.; Đerđ, I.; Štefanić, G.; Musić, S. Acoustic Vibrations of Amorphous and Crystalline $\mathrm{ZrO}_{2}-\mathrm{TiO}_{2}$ Nanoparticles. J. Mol. Struct. 2014, 1073, 119-124.

(29) Saviot, L.; Machon, D.; Mermet, A.; Murray, D. B.; Adichtchev, S.; Margueritat, J.; Demoisson, F.; Ariane, M.; Marco de Lucas, M. C. Quasi-Free Nanoparticle Vibrations in a Highly Compressed $\mathrm{ZrO}_{2}$ Nanopowder. J. Phys. Chem. C 2012, 116, 22043-22050.

(30) Saviot, L.; Murray, D. B. Vibrations of Weakly-Coupled Nanoparticles. Phys. Rev. B: Condens. Matter Mater. Phys. 2010, 81, 235432.

(31) Marquardt, H.; Gleason, A.; Marquardt, K.; Speziale, S.; Miyagi, L.; Neusser, G.; Wenk, H.-R.; Jeanloz, R. Elastic Properties of $\mathrm{MgO}$ Nanocrystals and Grain Boundaries at High Pressures by Brillouin Scattering. Phys. Rev. B: Condens. Matter Mater. Phys. 2011, 84, 064131.

(32) Ayouch, A.; Dieudonné, X.; Vaudel, G.; Piombini, H.; Vallé, K.; Gusev, V.; Belleville, P.; Ruello, P. Elasticity of An Assembly of Disordered Nanoparticles Interacting via Either Van Der Waals-
Bonded or Covalent-Bonded Coating Layers. ACS Nano 2012, 6, 10614-10621. 